\section{The Parasitic Worms.}

A Manual of Helminthology: Medical and Veterinary. By Dr. H. A. Baylis. Pp. xi +303 . (London: Baillière, Tindall and Cox, 1929.) $30 s$. net.

$T^{\mathrm{T}}$ is rare indeed to find a text-book of general or 1 economic zoology which treats of the parasitic worms without introducing some errors, often gross errors, although in dealing with the other phyla it may be strictly accurate. This, in the past, has been, in part at least, due to the fact that no good modern text-book on helminthology has been available. With the appearance of Dr. Baylis's work on the subject, that excuse is removed. In a matter of 300 pages, the author, briefly and concisely, provides such short descriptions of the genera and species of helminths of man, the domestic mammals and birds, as will, with the aid of the illustrations, enable the reader to obtain at least an approximate determination of most of the parasites which he is likely to meet.

The book falls into two parts, the first dealing with the flat-worms, and the second with the round-worms. Each part commences with a general account of the anatomy, then proceeds to consider, family by family, the parasites of medical and veterinary importance, their occurrence and morphology, and the more important facts of their life-histories so far as they are known. The clinical and pathological aspects of the subject are not considered and the volume is essentially a zoological one. The classification used is a natural one, so far as our present knowledge makes this possible; and in order to correlate the parasites of each host, a classified index to the parasites of the more important animals or animal groups is appended. The nomenclature used is up-to-date; but to avoid confusion with other names which have enjoyed long, though incorrect, use, the more common and well-known synonyms are usually given as well, the correct names being printed in heavy, conspicuous type.

There is no need to emphasise the importance of this subject in both medical and veterinary medicine, and helminthology is now an essential part of the curriculum of every student of these subjects, either as part of his initial training in zoology or as a separate course later on, or as both. There is accordingly a real necessity for an accurate, authoritative text-book such as this. It has its limitations ; limitations set by the extent of presentday knowledge of the parasitic worms, by the omission of parasites of wild or partially domestic- ated animals (such as elephants and rabbits), and by the absence of pathological and clinical helminthology. To have included these, however, would have required a work of encyclopædic proportions, and correspondingly prohibitive price. Within these limitations, Dr. Baylis has done his work well and has produced a text-book of immense value, especially to those interested in zoological helminthology. The manual is well and clearly written, adequately illustrated, and strongly produced, and should meet with a ready response among zoologists, medical men, and veterinary surgeons.

\section{Our Bookshelf.}

Ibn Battúta, Travels in Asia and Africa, 1325-1354. Translated and selected by H. A. R. Gibb. (The Broadway Travellers.) Pp. vii $+398+8$ plates. (London: George Routledge and Sons, Ltd., 1929.) I5s. net.

"The Broadway Travellers" offers to the public in popular form a store of entertaining reading as well as a series of valuable records, many of which are not otherwise readily available. By including in this series the travels of Ibn Battúta, which are now for the first time made accessible to the English reader, the editors have earned the gratitude of all students of travel literature who are not professed orientalists. Ibn Battúta stands in the first rank of medieval travellers. As a Moslem he gives a picture of the eastern world which not only differs in perspective but is at the same time truer and more intimate than that of the European travellers of about his own time. Granted the difference in orientation, the general attitude of mind of this traveller is more readily comprehensible to the modern reader than that of the medieval Christian.

Ibn Battúta, who was born at Tangier in 1304, set out on his travels at the age of twenty-one. His aim was to accomplish the pilgrimage to Mecca, but he was diverted by circumstances and traversed the whole of Syria before reaching the Holy City. A visit to Iraq was followed by three years' theological study in Mecca, during which time he formed the project of visiting India, but before doing so he visited the trading stations of East Africa. Then India was reached by way of Asia Minor and Central Asia. After a stay of some seven years at Delhi he was sent as an envoy to China. When he returned to his native land after 1348 he had covered a distance estimated at 75,000 miles. He died in 1368 or 1369 . The mere recital of the countries visited and the distances covered, however, gives a very meagre idea of the value of his record. His intellectual qualifications and standing as a qádi and his consequent interest in theology, combined with his intensely human personality, give his record an interest which is surpassed by no book of travel of his own and not many of a later day.

$$
\text { No. } 3120 \text {, VoL. 124] }
$$

